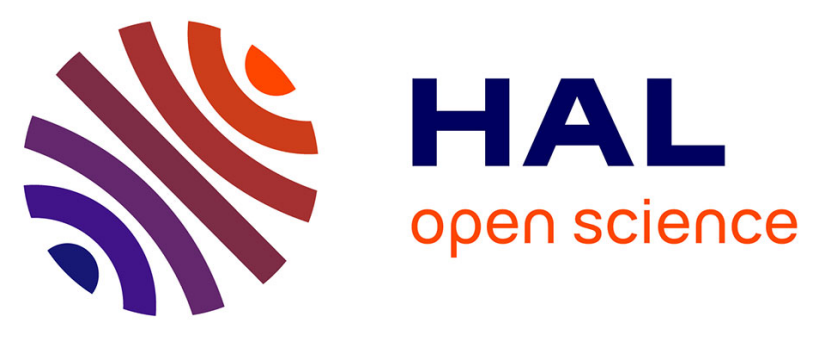

\title{
Determination of the pressure in micrometric bubbles in irradiated nuclear fuels
}

\author{
Rébecca Dowek, Céline Cagna, Jean Noirot, Isabelle Zacharie-Aubrun, \\ Thierry Blay, Karine Hanifi, Philippe Bienvenu, Ingrid Roure, Martiane \\ Cabié, Myriam Dumont
}

\section{To cite this version:}

Rébecca Dowek, Céline Cagna, Jean Noirot, Isabelle Zacharie-Aubrun, Thierry Blay, et al.. Determination of the pressure in micrometric bubbles in irradiated nuclear fuels. Journal of Nuclear Materials, 2021, 543, pp.152591. 10.1016/j.jnucmat.2020.152591 . hal-03385660

\section{HAL Id: hal-03385660 https://hal.science/hal-03385660}

Submitted on 19 Oct 2021

HAL is a multi-disciplinary open access archive for the deposit and dissemination of scientific research documents, whether they are published or not. The documents may come from teaching and research institutions in France or abroad, or from public or private research centers.
L'archive ouverte pluridisciplinaire HAL, est destinée au dépôt et à la diffusion de documents scientifiques de niveau recherche, publiés ou non, émanant des établissements d'enseignement et de recherche français ou étrangers, des laboratoires publics ou privés. 


\title{
Determination of the pressure in micrometric bubbles in irradiated nuclear fuels
}

\author{
Rébecca Dowek ${ }^{a}$, Céline Cagna ${ }^{a}$, Jean Noirot ${ }^{\mathrm{a}, *}$, Isabelle Zacharie-Aubrun ${ }^{\mathrm{a}}$, Thierry Blay ${ }^{\mathrm{a}}$, \\ Karine Hanifi ${ }^{a}$, Philippe Bienvenu ${ }^{a}$, Ingrid Roure ${ }^{a}$, Martiane Cabié ${ }^{b}$, Myriam Dumont ${ }^{c}$ \\ a CEA, DES, IRESNE, DEC, Cadarache F-13108 Saint-Paul-Lez-Durance, France \\ ${ }^{\mathrm{b}}$ Aix Marseille Univ., CNRS, FSCM, CP2M, France \\ cArts et Métiers Institute of Technology, MSMP, HESAM Université, F-59000 Lille, France
}

Keywords:

Uranium dioxide

Irradiated fuel

Fission Gas

Bubble pressure

\begin{abstract}
A B S T R A C T
In oxide nuclear fuels, at high burn-up or during high temperature periods such as ramp tests, out-ofpile heating tests, or any irradiations at high linear heat rates, fission gases can form micrometric or quasi-micrometric bubbles. During nominal operations, these bubbles participate to the pellet swelling, to the decrease of the fuel thermal conductivity and are involved in the mechanisms leading to fission gas release. During events involving a temperature increase, the resulting increase in the internal pressure of the bubbles might play a role in fuel fragmentation and in the opening of grain boundaries. The gas densities inside these bubbles are therefore one of the useful experimental information for the understanding of the fuel behaviour, and for the fuel behaviour code progress and validation. Two methods were developed to evaluate the gas density in the quasi-micrometric bubbles, using electron probe micro analyser, secondary ion mass spectrometry and focused ion beam scanning electron microscope together. The first method provides a mean gas density for all quasi-micrometric bubbles in a given area. The second method provides a gas density in a single selected bubble. In addition to the gas density, the 3D size and shape of the selected bubble is measured and can be related to the gas density result. In this work, these methods were applied to the bubbles formed in the centre of a PWR $\mathrm{Cr}$ doped $\mathrm{UO}_{2}$ at $38.8 \mathrm{GWd} / \mathrm{t}_{\mathrm{U}}$ after a ramp test in the Osiris reactor, with a $12 \mathrm{~h}$ plateau at $470 \mathrm{~W} / \mathrm{cm}$, and to the bubbles formed in a PWR $\mathrm{Cr}$ doped $\mathrm{UO}_{2}$ at $62.8 \mathrm{GWd} / \mathrm{t}_{\mathrm{U}}$ in the centre of the pellet and on the bubbles of the high burn-up structure on the rim. Both show the high pressures reached in these bubbles.
\end{abstract}

\section{Introduction}

During nuclear fuel irradiation, fission reactions lead to a gradual build-up of fission products in the material. About $15 \%$ of these products are gaseous species (mainly xenon and krypton). A fraction of these gases are released in the free volumes of the rods $[1,2]$, but most of them remain in the fuel matrix, as isolated atoms or in bubbles. Bubbles can form inside the grains and on the grain boundaries of the fuel, and their sizes may range from nanometric to micrometric scales. Their distribution (size, shape and density) is dependent on the burn-up, the irradiation conditions and the radial position in the pellet [1,3-5]. In Pressurized Water Reactor (PWR) fuels, micrometric bubbles appear in the pellets at high burn-up mainly in the central part [6,7] (Fig. 1a), and on the rim [6] (Fig. 1b), with the formation of the so-called High Burn-up
Structure (HBS) $[4,8,9]$. Such micrometric bubbles also form in case of high temperature excursions [10], i.e. irradiations at high linear power in Material Testing Reactors (MTR) (Fig. 1c). Such high temperature conditions can also be imposed out-of-pile, during high temperature tests in hot cell facilities.

Bubbles contribute significantly to the fuel's behaviour during nominal operations: they participate to the pellet swelling, to the decrease of the fuel thermal conductivity, and they are involved in the mechanisms leading to fission gas release. During events involving a temperature increase, such as LOCA (Loss Of Coolant Accident) or RIA (Reactivity Insertion Accident), the internal pressure of the bubbles increases accordingly. This can lead to fuel fragmentation or to the opening of grain boundaries [11-13]. Consequently, numeric codes used in the modelling of the fuel behaviour include fission gas models [2,14-17]. To provide accurate data for modelling, a thorough characterization of fission gases, particularly of bubbles at different scales, is therefore required. Among all needed parameters, pressure inside bubbles is one important feature but 

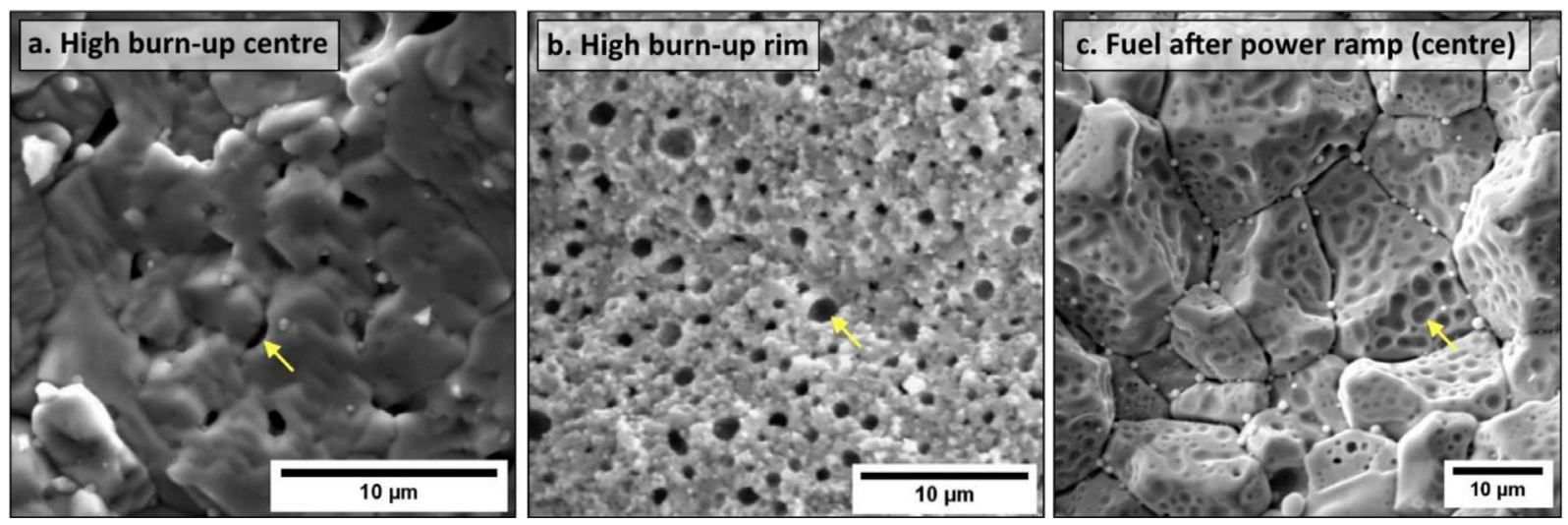

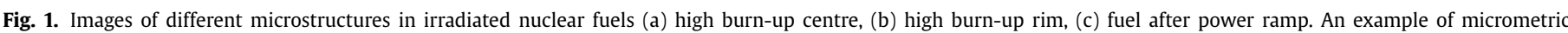
bubble is pointed out by an arrow in each image.

particularly complex to determine, as direct measurement is not possible. Bubble pressure estimation requires coupling of different experimental techniques to determine the molar volume of gases, as well as the use of a proper equation of state for fission gases. Moreover, pressure is supposed to evolve during irradiation and to be bubble size-dependent.

Several studies proposed experimental methodologies in order to measure the mean molar volume of the fission gases in the micrometric bubbles. In all cases, the procedure consisted in the measurement of the amount of fission gases contained in bubbles, and in the measurement of the volume occupied by these bubbles. Only techniques and analysis used to determine these values differed.

In the method used by Noirot et al. [4], EPMA (Electron Probe Micro-Analyser) measurements were performed to determine the local amount of xenon contained in the bubbles, and the local porosity was determined by image analysis of SEM (Scanning Electron Microscopy) micrographs. This was applied to determine the molar volume of micrometric bubbles formed in the HBS on the rim of irradiated $\mathrm{UO}_{2}$ pellets, and in plutonium rich agglomerates of mixed oxide fuels (MOX). In this paper, only values for the rim HBS of $\mathrm{UO}_{2}$ samples are reported. In [4], SIMS (Secondary Ion Mass Spectrometry) xenon measurements showed that the release was extremely low on the periphery of the irradiated $\mathrm{UO}_{2}$ samples. The local quantity of fission gases contained in the bubbles was then derived from EPMA measurements, more precisely from the difference between the xenon concentration produced by fission, and the xenon concentration remaining in the fuel matrix as isolated atoms or nanometric bubbles [18]. To obtain this gas production, EPMA was used to measure the neodymium concentration, approximately proportional to the local burn-up. Finally, the porosity of the fuel was obtained by the analysis of SEM 2D images. Resulting molar volumes obtained in $\mathrm{UO}_{2}$ rim are summarized in Table 1 . In this paper, pressure evaluation was performed by using the Van der Waals EOS (Equation Of State) at 650K. However, based on the work of (28), and considering the range of molar volumes, the EOS proposed by Soave (29) seems to be more accurate and will be used further in this paper. As a consequence, for the sake of comparison, pressures recalculated according to Soave's EOS are also displayed in Table 1, for results from the literature, when all data necessary for the calculation are available. The results in [4] demonstrated that rim HBS bubbles were highly pressurized, even with a systematic overestimation of the parameters resulting in a minimized pressure determination.

Walker et al. [19], carrying out a study on irradiated PWR fuels, used a similar approach with SIMS to confirm the very low release, and EPMA to quantify fission gases in the rim bubbles. They also found a high pressure of $45 \mathrm{MPa}$ at room temperature in $\mathrm{HBS}^{\mathrm{U}} \mathrm{UO}_{2}$ rim bubbles in a fuel irradiated at low temperatures. This time, the Brearly and MacInnes (B\&MI) EOS was used. In Table 1, the pressure was recalculated at $293 \mathrm{~K}$ using the Soave EOS. In addition, the size distribution of HBS bubbles was also studied. The mean pore equivalent circle diameter (ECD), and the diameter class with the highest bubble density are displayed in Table 1 .

Horvath et al. [20] conducted experimental quantification of fission gases, using Laser Ablation Inductively Coupled with Plasma Mass Spectrometry (LA-ICP-MS). This technique was applied on the HBS rim of a very high burn-up PWR fuel. The quantity of gas contained in bubbles was measured by several large laser shots (diameter $\sim 50 \mu \mathrm{m})$. The porosity was determined by SEM. The ablated volume was obtained using an optical microscope. Again, a high pressure, similar to the previous values, was found. In addition to this mean value, local analyses were conducted on this sample with smaller laser spots $(15 \mu \mathrm{m})$ aiming to open only one bubble for each laser pulse. However, quantitative measurement of individual bubbles was not achieved, as the bubble size and bubble density, estimated from the SEM, provided a basis of 2 to 4 bubbles opened for each laser pulse, with a diameter ranging from 2 to $7 \mu \mathrm{m}$. Consequently, the range of pressure deduced remained wide, from $0.4 \mathrm{MPa}$ to $35 \mathrm{MPa}$.

Noirot et al. [21,22] improved the gas quantification process using the SIMS for gas measurements, and not only EPMA. Thereby, the method was extended to cases where fission gases are partially released. Indeed, in such cases, it is not possible to directly deduce the total amount of gas in the fuel from the amount of gas produced during irradiation. It therefore becomes necessary to have a method that measures both the total quantity of gas in the fuel and the quantity of gas as isolated atoms (or nano-bubbles) in the material, which is possible with SIMS calibrated by EPMA. The gas contained in micrometric bubbles is then the difference between these two values. The method is detailed in section 2.2. This improved methodology was used to estimate the mean pressure of gas in micrometric bubbles of a UO2 fuel discs sandwiched between Mo discs, irradiated in the Halden Boiling Water Reactor within the NFIR program [22]. Considering the irradiation conditions (very high final burn-up around $103 \mathrm{GWd} / \mathrm{t}_{\mathrm{U}}$ and low irradiation temperature between $560^{\circ} \mathrm{C}$ and $700^{\circ} \mathrm{C}$ ), these $\mathrm{UO}_{2}$ discs were comparable to the rim of a standard pellet. This method was also applied to characterize micrometric bubbles localized in the centre and on the rim of a standard $\mathrm{UO}_{2}$ pellet in [1], and micrometric bubbles of the centre in [23].

Results from these articles are summarized in Table 1.

Considering these results, it appears that the different procedures used to measure the molar volume agree to state that mi- 


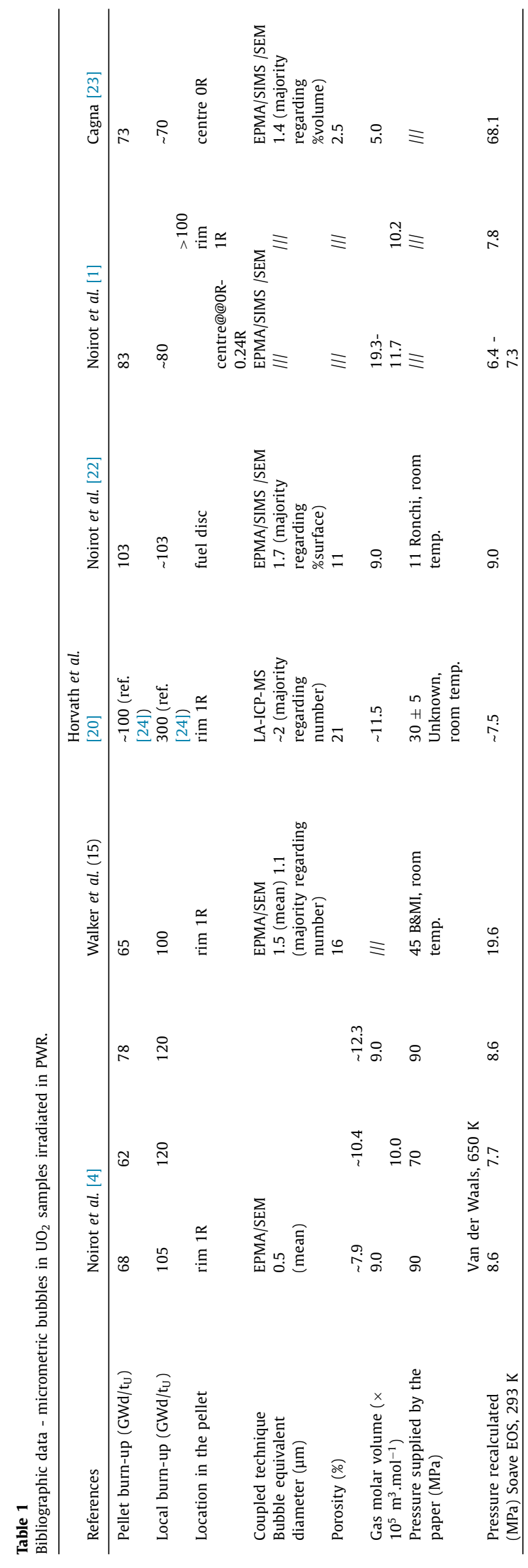

crometric bubbles are highly pressurized in the high burn-up irradiated $\mathrm{UO}_{2}$ pellets. However, data are mainly focused on the rim HBS bubbles, with pressures at room temperature found from 7 to $20 \mathrm{MPa}$. Few data are available concerning the pellet's centre, with a higher scattering, from $6 \mathrm{MPa}$ to $68 \mathrm{MPa}$. Moreover, the size distribution of bubbles is known to be wide. As the pressure is expected to be size-dependent, a deeper knowledge on the size effect on pressure as a function of the irradiation conditions is still needed.

This article aims to bring new measurements for micrometric bubbles, both in the rim HBS and in the centre of fuels irradiated in PWR, by using a mean molar volume quantification by coupling SIMS, EPMA and SEM. Moreover, a new experimental approach was carried out to determine the gas molar volume of single bubbles. This allows to determine the gas pressure in selected bubbles of known size and then to explore the size effect on pressure inside micrometric bubbles.

\section{Experimental}

\subsection{Samples}

The first sample used for this study was a cross section of a large-grain $\mathrm{UO}_{2}$ fuel rod, with an initial ${ }^{235} \mathrm{U}$ enrichment of $4.89 \%$. These large grains, with an average size of $64 \mu \mathrm{m}$ in diameter, were obtained by the addition of chromium $\left(\mathrm{Cr}_{2} \mathrm{O}_{3}\right)$ in the UO2 powder before pressing and sintering of the pellets. It was irradiated for two annual cycles in a PWR. The fuel was then ramp tested at 470 W. $\mathrm{cm}^{-1}$ with a 12-hour plateau in the Osiris MTR. The rod did not fail during this ramp test. The burn-up at the sampling position was $38.8 \mathrm{GWd} / \mathrm{t}_{\mathrm{U}}$. As the ramp was short, it did not significantly increase this burn-up. This $\mathrm{UO}_{2}$ sample is referred to as sample $\mathbf{A}$ in the following.

The second sample is a cross section of a large-grain UO2 fuel rod with an average grain size around $60 \mu \mathrm{m}$, also obtained by the addition of chromium in the UO2. The fuel was irradiated in a PWR. The average burn-up of the rod was $63.8 \mathrm{GWd} / \mathrm{t}_{\mathrm{U}}$, but the burn-up at the sampling position was a bit lower, $62.8 \mathrm{GWd} / \mathrm{t}_{\mathrm{U}}$. This high burn-up sample irradiated in standard conditions is referred to as sample $\mathbf{B}$.

The samples were embedded in a low melting point Sn-Bi alloy under vacuum. Then, their surface was mechanically polished with $\mathrm{SiC}$ and then with diamond suspensions down to $0.25 \mu \mathrm{m}$ grade. The final step of the polishing was realized with a colloidal suspension of silica with a particle size of $0.02 \mu \mathrm{m}$. Fabrication characteristics, burn-up and main features for both samples are summarized in Table 1.

\subsection{Techniques}

The samples were characterized by FIB-SEM (FIB=Focused Ion Beam), EPMA and SIMS. All devices are operated in shielded hot cells in the CEA LECA-STAR facility at Cadarache (France), and have been modified to allow examination of irradiated fuel samples.

The FIB-SEM was a shielded dual beam microscope Auriga 40 (Carl Zeiss, Oberkochen, Germany). It was used in this work both for surface 2D imaging (section 3.1) and for 3D tomography by serial cuts (section 3.2). Surface imaging is done concomitantly with back scattered electron detector and a secondary electron detector. Images performed with back scattered electron detector were used for image analysis quantitative measurements, the other images had only qualitative information. Beam acceleration voltages are detailed in the course of the text. The tomography is a complex acquisition process. First, a platinum (Pt) layer is grown by FIB induced deposition, to cover the area of interest on the sample surface. An excavation is then made by abrasion of the material using 


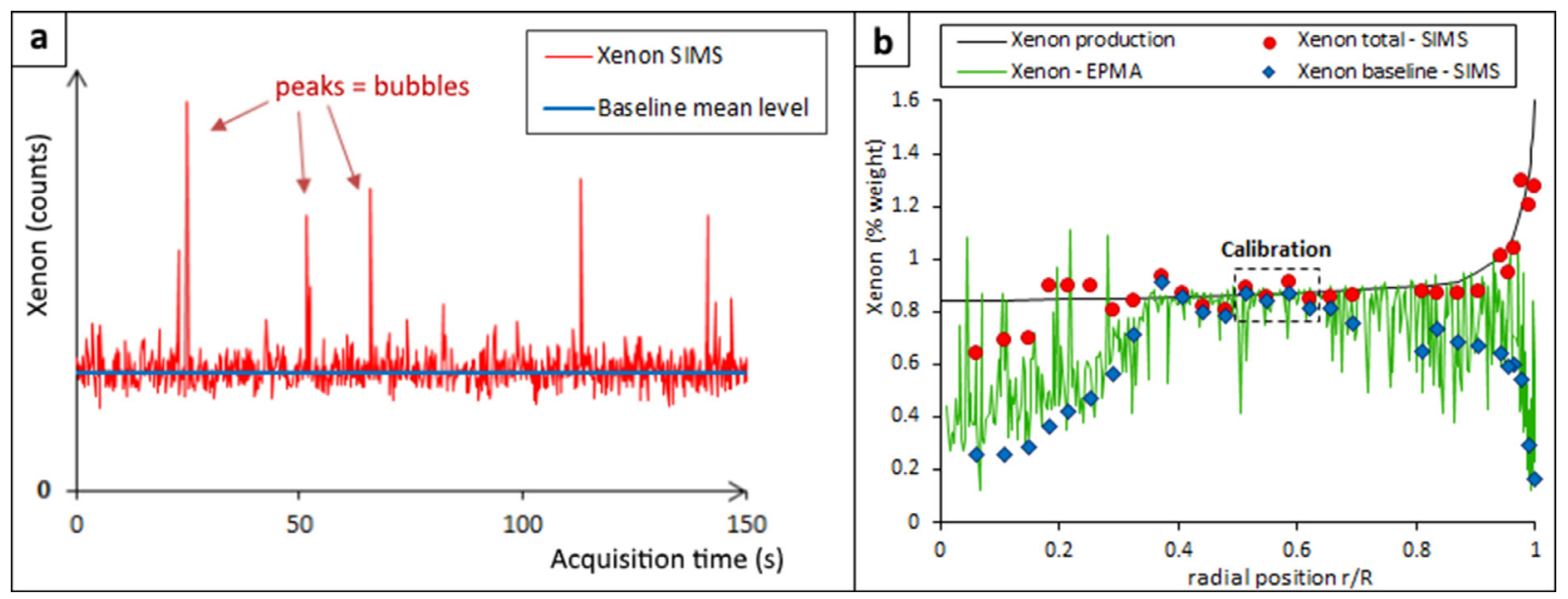

Fig. 2. Sample B - ${ }^{132}$ Xe SIMS measurement of an irradiated nuclear fuel (a) SIMS profile (b) SIMS-EPMA calibration of the sample.

the FIB perpendicular to the sample, with a high voltage. The wall of the excavation is then gradually smoothed. It forms the starting plane for the acquisition. Finally, the actual tomography begins: an alternation between abrasion of a thin layer of material with the FIB and imaging of the newly revealed wall with the SEM. It results in a series of consecutive 2D images, or serial cuts, forming a stack of images. After an alignment step and additional post-processing steps (background correction, noise reduction...), the 3D volume is reconstructed assuming that the pixel observed on a $2 \mathrm{D}$ image is representative of the voxel between this $2 \mathrm{D}$ image and the following 2D image. The FIB is used with a current $600 \mathrm{pA}$. The conditions of imaging are detailed gradually in the text. It must be noted that during the tomography, FIB and SEM columns form a $54^{\circ}$ angle. Images of each cut must therefore be numerically corrected after acquisition.

The EPMA was a SX100-R micro-beam from CAMECA. Xenon radial distribution (section 3.1 and 3.2) and maps (section 3.2) were measured for this work. Radial distributions were done by quantitative punctual analyses every $10 \mu \mathrm{m}$, and then every $2 \mu \mathrm{m}$ on the first $100 \mu \mathrm{m}$ from the edge on a chosen pellet radius. The radial distribution measurements were done at an electron acceleration voltage of $20 \mathrm{kV}$ and an incident beam current of $200 \mathrm{nA}$. Quantitative results were obtained, as a mass percentage of xenon in the irradiated $\mathrm{UO}_{2}$, thanks to prior calibration on a reference standard sample, with the same conditions. For xenon, this reference was a multi-characterized $25 \mathrm{GWd} / \mathrm{t}_{\mathrm{U}} \mathrm{UO}_{2}$, the same as for [25]. Regarding the xenon maps, they were composed of $512 \times 512$ pixels, and covered an area of $200 \times 200 \mu \mathrm{m}^{2}$ for sample $\mathbf{A}$, and $150 \times 150 \mu^{2}$ for sample B, at $30 \mathrm{kV}-200 \mathrm{nA}$ conditions. Each pixel required $30 \mathrm{~ms}$ for acquisition.

SIMS measurements were performed with an IMS 6f-R from CAMECA. Xenon can be measured, thanks to its ionization under the primary beam [26]. The isotope measured was ${ }^{132} \mathrm{Xe}$, as the best compromise between the ratio ${ }^{132} \mathrm{Xe} / \mathrm{Xe}$, the ability to be collected by the spectrometer, and the relatively low interferences from other species. SIMS was used first to obtain a relative radial xenon distribution. The primary beam was generated from an oxygen ion source $\left(\mathrm{O}_{2}{ }^{+}\right)$, at an acceleration voltage of $15 \mathrm{kV}$, and with a current about $60 \mathrm{nA}$. Further details on the SIMS settings are exposed in [26]. The radial distribution was done through punctual fixed measurements, resulting in craters in the material, approximately every $150 \mu \mathrm{m}$ along the same radius as for EPMA. For each point, 5,000 acquisitions were done, at a rate of one acquisition every $0.2 \mathrm{~s}$, providing a result in counts detected by the spectrometer. The volume of each crater $V_{c}$ was measured afterwards by profilometry (profilometer STIL, with a step $1 \mu \mathrm{m}$ ). The measured val- ues were about $7,000 \mu \mathrm{m}^{3}$ in the previously stated conditions. For this work, the volume of each crater was controlled by profilometry (profilometer STIL, with a $1 \mu \mathrm{m}$ step). The first 150 seconds of a typical SIMS measurement is displayed in Fig. 2a. For the single bubble measurement, SIMS is used with exactly the same conditions (primary beam, acquisitions and isotope), apart from the acquisition time since the acquisition is stopped as soon as the selected bubble is opened (cf. 3.2).

In the method used in $[1,22,23]$ to estimate mean molar volume of gas in micrometric bubbles, EPMA and SIMS are coupled to perform gas quantification. A typical SIMS measurement is displayed on Fig. 2a. It was evidenced [27] that a SIMS xenon measurement, representative of all the gas remaining in the $\mathrm{UO}_{2}$ fuel, consists of two components: a baseline, which is associated to ${ }^{132} \mathrm{Xe}$ present as isolated atoms or in nanometric bubbles, and peaks, corresponding to the opening of one or a few bubbles. The dissociation between these two parts, described in [28], gives the local relative quantity of fission gas contained in the micrometric bubbles. EPMA measurements are then used to calibrate the SIMS measurements (Fig. 2b). This is done by the superimposition of the different radial profiles, in a zone where precipitation and release are minimal, and considering that the ratio ${ }^{132} \mathrm{Xe} / \mathrm{Xe}$ is almost constant over the pellet radius. EPMA gives a value for the mass concentration of xenon in the fuel. If the EPMA average value in the zone of calibration is noted $w_{X e}$, and the average counts intensity measured by the SIMS is noted $I$, the calibration constant $C$ in mol per counts, is expressed by:

$C=\frac{w_{X e}}{I} \cdot \frac{V_{c, \text { mean }} \cdot \rho_{U O_{2}}}{M_{X e}}$

with $V_{c, \text { mean }}$ the mean volume of SIMS craters in this location $\left(\mu \mathrm{m}^{3}\right), \rho_{U O_{2}}$ the density of the $\mathrm{UO}_{2}$ sample $\left(\mathrm{g} \cdot \mu \mathrm{m}^{-3}\right)$, and $M_{X e}$ the xenon molar mass (g.mol ${ }^{-1}$ ).

After such a calibration, SIMS measurements give the quantitative amount of xenon $n_{X e}$ contained in micrometric bubbles in the fuel, as a function of the radial position (OR refers to the centre of the rod and $1 \mathrm{R}$ to the rim). Knowing the production molar ratio $r=\mathrm{Xe} / \mathrm{Kr}$ thanks to neutron calculation [29], the quantitative amount of fission gases is:

$n=n_{X e}(1+1 / r)$

It should be noted that $\mathrm{Xe} / \mathrm{Kr}$ ratio and gas isotopies used here are calculated for each sample (cf. Table 2) but that their radial changes are neglected. Using SEM porosity $p$, gas molar volume in micrometric bubbles $v_{m}$ can be estimated for bubbles at 
Table 2

$\mathrm{UO}_{2}$ samples A and B - fabrication characteristics ( ${ }^{235} \mathrm{U}$ enrichment, initial grain size), irradiation characteristics (burn-up, gas release of the rods) and calculations (molar ratio $\mathrm{Xe} / \mathrm{Kr}$ and temperature at the centre of sample, at the end of the irradiation).

\begin{tabular}{lllllll}
\hline Sample & ${ }^{235} \mathrm{U}$ enrichment & Initial grain size & Burn-up (GWd/t $\left.\mathrm{t}_{\mathrm{U}}\right)$ & Gas release (\%) & $\mathrm{Ratio} \alpha=\mathrm{Xe} / \mathrm{Kr}$ & $\mathrm{Temperature}(\mathrm{end}$ of irradiation) \\
\hline A ramped & $4.89 \%$ & $\approx 64 \mu \mathrm{m}$ (centre) & $\mathbf{3 8 . 8}$ (2 cycles) & $7,52 \%$ & 9.0 & $1878^{\circ} \mathrm{C}(\mathrm{centre}, \mathrm{ramp})$ \\
B not ramped & $4.89 \%$ & $\approx 60 \mu \mathrm{m}$ (centre) & $\mathbf{6 2 . 7}$ (4 cycles) & $3,04 \%$ & 9.7 & $840^{\circ} \mathrm{C}\left(\right.$ centre) $380^{\circ} \mathrm{C}($ rim) \\
\hline
\end{tabular}

a selected radial position, even if local gas release had occurred: $v_{m}=p \times V_{c} / n$, with $V_{c}$ the volume of the crater resulting of the SIMS measurement [28].

\section{Results}

In this section, the mean densities of the two samples were calculated with the quantification of gas combining SIMS and EPMA, and the porosity determined by SEM image analysis. The procedure was applied to a large population of micrometric bubbles, leading to a mean molar volume determination. The approach was then refined to measure the gas density in one single bubble. From the molar volume obtained, pressures at selected temperatures were deduced.

Considering that all the molar volumes obtained were higher than $4.0 \times 10^{-5} \mathrm{~m}^{3} \cdot \mathrm{mol}^{-1}$, the Soave equation of state was used [23]. The equation is a modification of the Redlich-Kwong equation, both being a two parameters equations, with a more general second thermal member. The equation for the pressure $P$ was:

$P=\frac{R \cdot T}{v_{m}-b}-\frac{a(T)}{v_{m}\left(v_{m}+b\right)}$

with $R$ the gas constant $=8,315 \mathrm{~J} \cdot \mathrm{K}^{-1} \cdot \mathrm{mol}^{-1}, T$ the temperature (in $\mathrm{K}$ ), and $a(T)$ and $b$ the parameters depending on gas nature. They are formulated as follows:

$a(T)=0.42747\left(1+f\left(1-\sqrt{\frac{T}{T_{\text {crit }}}}\right)\right)^{2} \frac{R^{2} \cdot T_{\text {crit }}^{2}}{P_{\text {crit }}}$

with $f$ fugacity coefficient (dimensionless), and $T_{\text {crit }}$ and $P_{\text {crit }}$ respectively the critical temperature (in $\mathrm{K}$ ) and the critical pressure (in $\mathrm{Pa}$ ) for the gas being studied, and:

$b=0.08664 \frac{R \cdot T_{\text {crit }}}{P_{\text {crit }}}$

The critical temperature and pressure values are $f_{X e}=0.4926$, $T_{\text {crit, } X e}=289.7 \mathrm{~K}$ and $P_{\text {crit }, X e}=5.84 \times 10^{6} \mathrm{~Pa}$ for xenon, $f_{K r}=$ $0.4879, T_{\text {crit }, K r}=209,4 \mathrm{~K}$ and $P_{\text {crit }, K r}=5.50 \times 10^{6} \mathrm{~Pa}$ for krypton. $a(T)$ and $b$ have to be calculated for the gas mixture, considering the ratio $\alpha$ of the sample.

\subsection{Mean molar volume determination}

\subsubsection{Fuel after a power ramp - Sample A}

The SEM images in Fig. $3 a$ and $b$ illustrate respectively the centre $\mathrm{OR}$ and the radial position $0.75 \mathrm{R}$ of sample $\mathbf{A}$. These images were acquired with a secondary electron detector, with a beam acceleration voltage of $25 \mathrm{kV}$. In the centre, the large intergranular bubbles were highly interconnected, and formed a network through which part of the fission gases were released. The majority of these bubbles were therefore gas-empty cavities, and were not taken into account when measuring the porosity to establish the mean molar volume in bubbles full of gas. Outside this central area, between $0.75 R$ and $0.9 R$, very few bubbles were observed, as displayed in Fig. 3b (where intra-granular porosity is close to $0,2 \%$ ). This area was used as a calibration reference for the SIMS xenon measurements.
The 2D porosity was determined for sample $\mathbf{A}$ thanks to a binarization of SEM images, acquired with a backscattered electron detector at a beam acceleration voltage of $10 \mathrm{kV}$. Binarization is a process of assigning to each pixel of the image a label 0 or 1 , in order to split this image in two areas. Here, the two labels correspond to bubbles for 1 , and fuel (or non-bubble) for 0 . The discrimination was based only on a simple grey level threshold using the Otsu criterion [30]: bubbles were represented by pixels whose grey level is lower than a selected value. Among the bubble label, as explained above, for this sample, only the intra-granular porosity was considered: the grain boundaries were manually drawn and all bubbles on a grain boundary were removed from the measurement. This intra-granular porosity was $2.5 \%$ in the fuel centre. Then, a distribution of the surface fraction represented as a function of the bubble ECD was calculated: the class with the highest surface percentage was that of bubbles of ECD $2-2.2 \mu \mathrm{m}$, and the biggest class was for ECD 3.4-3.6 $\mu \mathrm{m}$, which is a small size compared to the observed area of $250 \times 190 \mu \mathrm{m}^{2}$.

SIMS measurements were conducted along a radius of the pellet. As said previously, the calibration was done for the referent area at a relative radial location around $0.8 \mathrm{R}$. In the centre, the total quantity of gas in the bubbles was found to be $3.17 \times 10^{-12} \mathrm{~mol}$, for $8177 \mu^{3}$ of fuel sputtered. Knowing the porosity, the corresponding bubble volume was $204.3 \mu \mathrm{m}^{3}$.

The molar volume was therefore $6.46 \times 10^{-5} \mathrm{~m}^{3} \cdot \mathrm{mol}^{-1}$, i.e. an atomic volume corresponding to 2.6 times the volume of one Schottky defect/atom $\left(\Omega=40.9 \AA^{3}\right)$. In the centre of sample $\mathbf{A}$, the mean pressure of all bubbles larger than about $0.1 \mu \mathrm{m}$ in diameter was evaluated to $20.5 \mathrm{MPa}$, for a temperature of $293 \mathrm{~K}$.

\subsubsection{High burn-up fuel - Sample B}

Fig. 4 illustrates the centre and the rim of sample $\mathbf{B}$, at the radial positions studied in this work. A secondary electron detector and a backscattered electron detector with a beam acceleration voltage of $15 \mathrm{kV}$ were used. Several images of the same area were acquired for each location, with a pixel size from $10 \mathrm{~nm}$ to $100 \mathrm{~nm}$. There was a high density of intra-granular bubbles in the central area (Fig. 4a and b), and of inter-granular bubbles on the rim of the pellet, with a typical rim HBS (Fig. 4c). In addition to these bubbles formed during the irradiation, fabrication pores exist in the fuel. Such pores were already visible on Fig. $3 \mathrm{~b}$, where they constitute the scarce small intra-granular cavities and bigger inter-granular cavities. On Fig. 4a and c, the two large single objects pointed out by yellow arrows were also fabrication pores. Indeed, almost all the small pores completely disappear during the early stage of the irradiation [31], but large pores remain. They are unrepresentative of the bubbles formed during irradiation, and are therefore not taken into account for the molar volume measurement. For this, a size threshold was fixed in order to dissociate the two types of objects, knowing the bubbles rarely exceed one micrometre in size: only objects with ECD smaller than $3 \mu \mathrm{m}$ were considered. Some pores validating this criterion could exist, but they are rare and not distinguishable from bubbles.

For sample B, SEM images at five radial positions were analysed, one at $1 \mathrm{R}$, with HBS, the others in the central area, respectively at $0 \mathrm{R}, 0.20 \mathrm{R}, 0.25 \mathrm{R}$ and $0.30 \mathrm{R}$. The surface fraction of the bubbles on the rim was $11.2 \%$, and it was between $1.5 \%$ at $0.30 \mathrm{R}$ and $4.1 \%$ at $\mathrm{OR}$, in the centre. These values are reported in Table 3. 

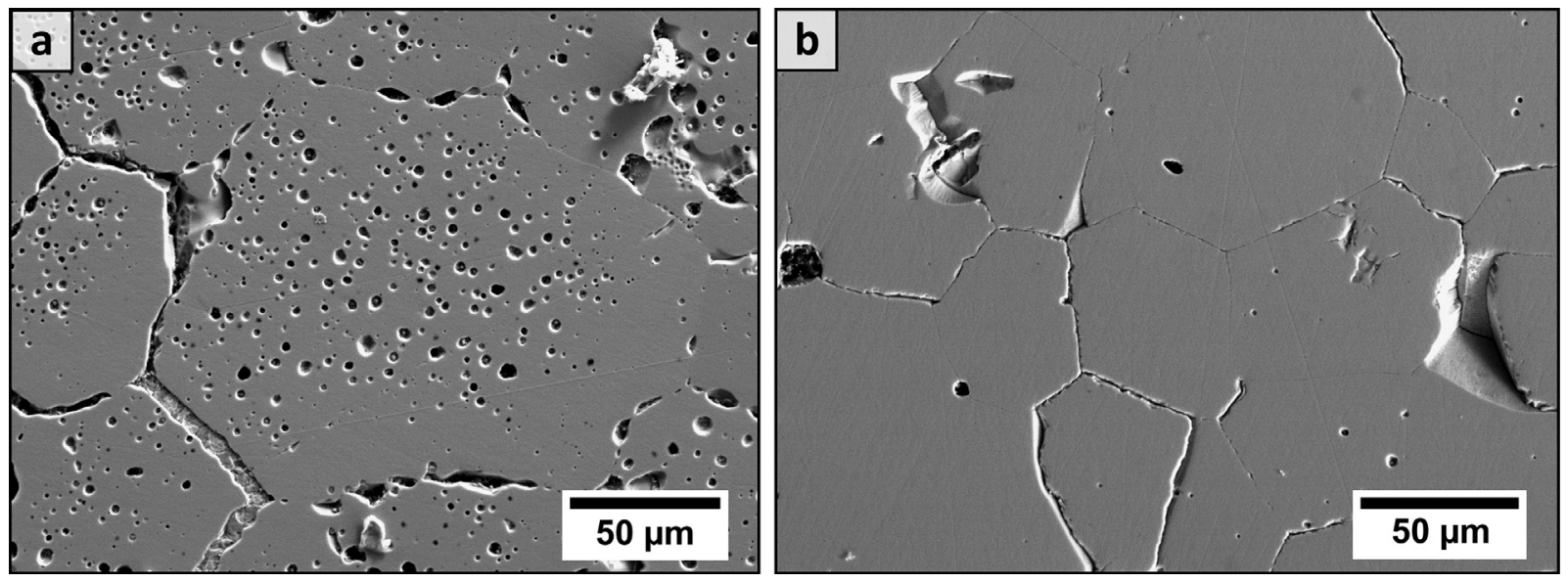

Fig. 3. Sample $\mathbf{A}$ - SEM images (a) at $\mathrm{OR}$ and (b) at $0,75 \mathrm{R}$.
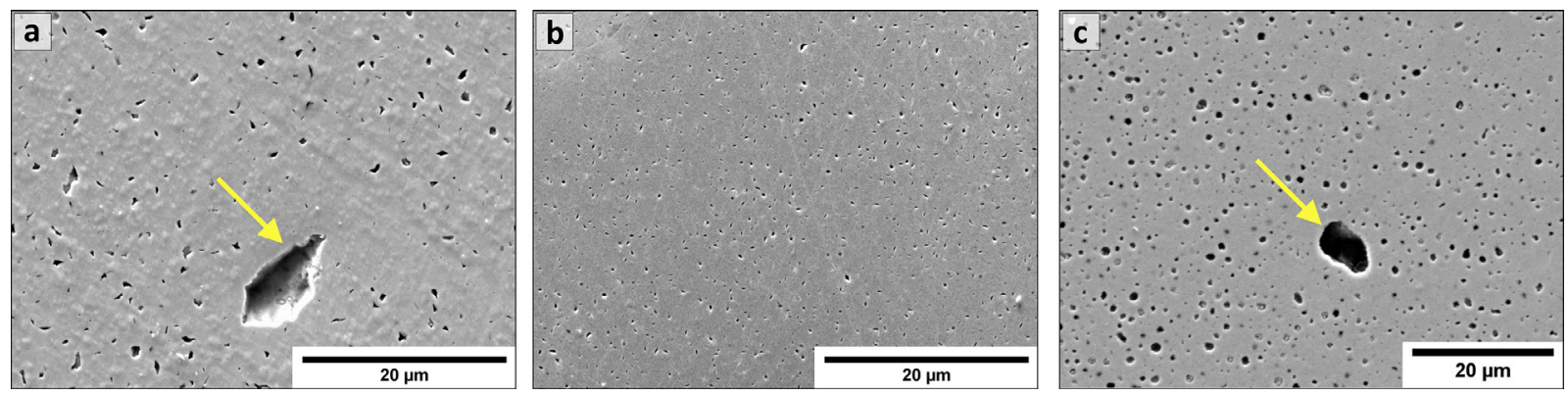

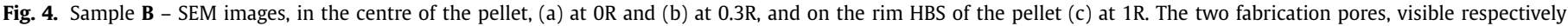
in (a) and (c), are pointed out by a yellow arrow.

Table 3

Sample B - Mean pressure in micrometric bubbles for several radial positions.

\begin{tabular}{llllll}
\hline & OR & $0.20 \mathrm{R}$ & $0.25 \mathrm{R}$ & $0.30 \mathrm{R}$ & $1 \mathrm{R}$ \\
\hline Porosity (\% area) & 4.1 & 3.4 & 2.6 & 1.5 & 11.2 \\
Xenon in micrometric bubbles (\%weight) & 3.9 & 5.1 & 4.3 & 2.5 & 11.1 \\
Molar volume of fission gases ( ${ }^{3} \cdot \mathrm{mol}^{-1}$ ) & $12.1 \times 10^{-5}$ & $8.3 \times 10^{-5}$ & $7.3 \times 10^{-5}$ & $8.4 \times 10^{-5}$ & $12.1 \times 10^{-5}$ \\
Atomic volume (Schottky defect/atom) & $4.92 \Omega$ & $3.36 \Omega$ & $2.98 \Omega$ & $3.42 \Omega$ & $4.92 \Omega$ \\
Mean pressure at 293 K - Soave (MPa) & 7.2 & 10.1 & 13.3 & 9.8 & 7.2 \\
\hline
\end{tabular}

The SIMS was then calibrated for sample $\mathbf{B}$ measurements (Fig. 2b). The \%weight of xenon contained in bubbles (relative to the total mass of the material) for each of these positions are also reported in Table 3 with the gas densities and pressures deduced from these measurements.

\subsection{Single-bubble - Molar volume}

The mean density measurements were applied on microstructures with a wide distribution of bubble sizes, between $0.1 \mu \mathrm{m}$ and $3 \mu \mathrm{m}$. This section is dedicated to the development of a complementary methodology, characterising the density in a single fission gas bubble, first in sample A centre, then in sample B centre and rim. The same set of equipment was used as in the mean density approach described in the previous section. The goal was to detect and to open a single selected bubble to measure its content, and then to measure its volume.

\subsubsection{Fuel after power ramp - Sample A}

Such a methodology, able to isolate a single bubble and evaluate the gas density in it, was first developed for sample A [23,32]. This methodology is referred to as the "single-bubble" process in the rest of this text. Sample A was chosen to be investigated first, because after such a power ramp, the bubbles in the fuel centre were large and scarcely distributed (Fig. 3). This made the measurement of a single bubble easier.

The characterization required several steps, described in Fig. 5.

Two bubbles were investigated for this sample, both located in the same area in the centre $(\mathrm{OR})$ of the sample, where the temperature was the highest during the ramp test.

Bubble selection. The first step a was the detection and the selection of a gas-filled bubble very close to the polished surface in this area. Its detection was allowed by SEM observations (Fig. 6a) with two different electron beam acceleration voltages, and so different material penetration. Here, voltages of respectively $10 \mathrm{kV}$ and $25 \mathrm{kV}$ were used. Step b is a comparison with the EPMA xenon map of the area (Fig. 6b), to confirm that the selected bubble appeared in this map as a bright spot, showing that it was full of fission gases.

Gas quantification. After the SIMS calibration (step c), SIMS xenon measurement was done on the selected bubble location for step $\mathrm{d}$, corresponding to the quantification part. For each bubble the sputtering was stopped immediately once a peak was measured (Fig. 7). After background subtraction, the peak area gave the 


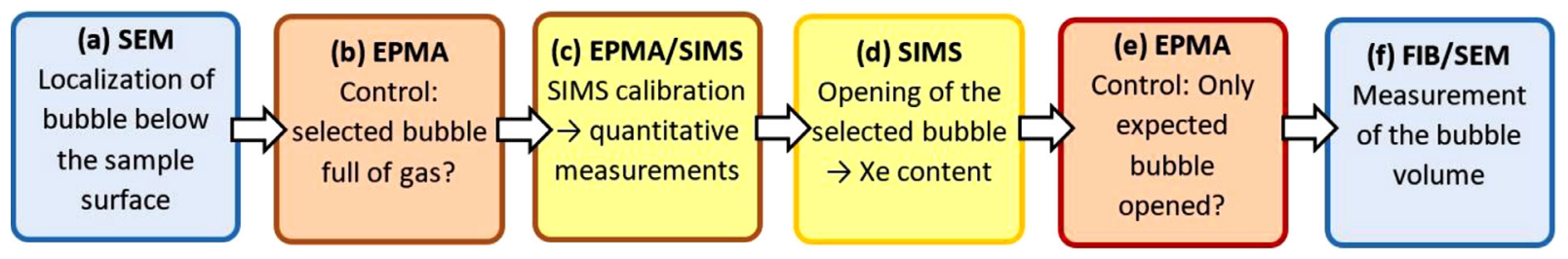

Fig. 5. Schematic view of the single-bubble process.
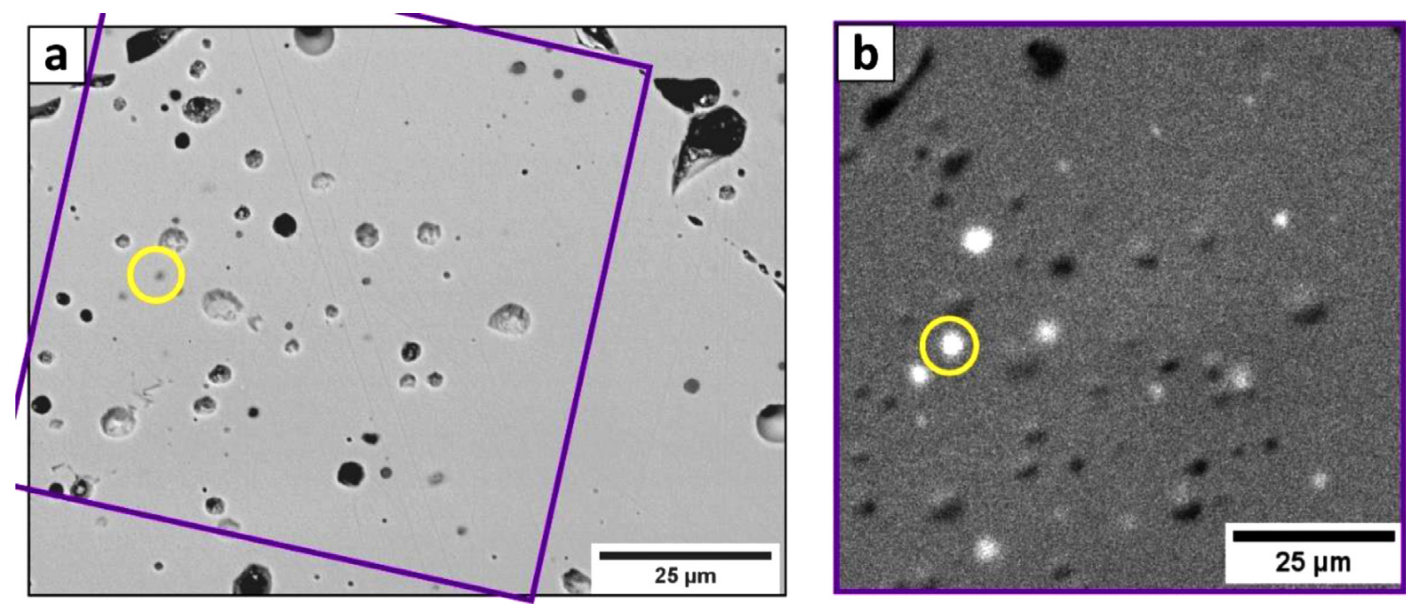

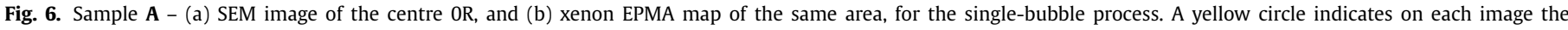
location of the selected bubble.

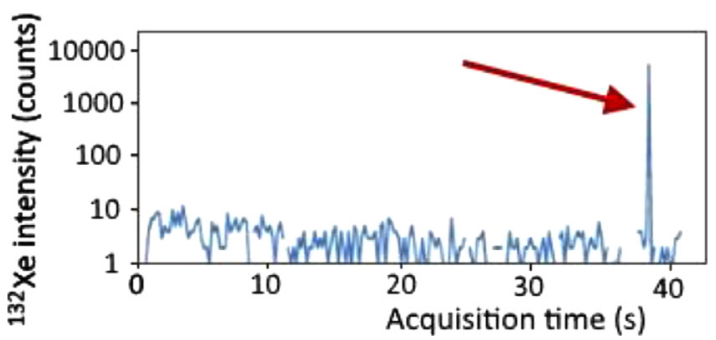

Fig. 7. Sample A - SIMS single-bubble measurement.

xenon content $n_{X e}$ of the selected bubble. From this quantity, the total fission gas content $n$ of the bubble was calculated, like for the mean pressure, knowing the xenon/krypton ratio $\alpha$ by equation (2). The quantity of fission gas (xenon + krypton) due to this peak was $1.03 \times 10^{-13} \mathrm{~mol}$ for the first bubble, and $1.62 \times 10^{-13} \mathrm{~mol}$ for the second one.

Bubble control. After the SIMS measurement, a second EPMA map (step e), confirmed that only the expected bubble was opened and emptied by showing a dark contrast in the place of the original white spot (Fig. 8). It is also possible to verify that no other bubble was affected by the SIMS beam.

Bubble volume. The selected bubble volume evaluations (step f) were done by the use of the FIB-SEM. In fact, in case of complex shapes [7], SEM image of the polished surface is unable to provide a good estimation of the size and volume of the object. With FIBSEM, a 3D tomography by FIB serial cuts was realized in the SEM for the selected bubble. This technique was possible, because the SIMS measurement was immediately stopped after the opening of the bubble. Consequently, the remaining cavity volume was almost unaffected by the SIMS beam. The mechanical properties of $\mathrm{UO}_{2}$ are such that the volume of the cavity did not change significantly when the gas escapes from the bubble.
For this tomography, serial cuts were made with a regular step of $40 \mathrm{~nm}$ step. Each image was acquired with a pixel of the same size, in order to obtain an image made of cubic voxels with 40 $\mathrm{nm}$ sides. To acquire the images of each cut, the secondary electron detector was used, with a beam acceleration voltage of $10 \mathrm{kV}$. Some of these aligned images are presented Fig. 9a, with a yellow arrow pointing out the measured bubble on each image. A Pt layer, deposited on the sample surface after the SIMS measurement and necessary in the SEM tomography process, is visible on each slice and is hatched in blue. On slice 10, where the bubble started, a sharp conical cavity is visible, it is simply a hole made by the FIB-SEM before the measurement. A red arrow indicates the point where the bubble reached the surface of the sample (slide 73). From this 3D tomography, a reconstruction of the bubble was performed, giving access to its volume $V_{\text {bubble }}$ and mean size. The Fig. $9 \mathrm{~b}$ is a volume rendering of this $3 \mathrm{D}$ reconstruction. The bubble shape was close to spherical, the depression visible at the top left is due to the presence of a metallic precipitate, visible on the slices 50-73-90. Such association bubble-precipitate is common.

Results. The molar volume $v_{m}$ was obtained directly by $v_{m}=$ $V_{\text {bubble }} n$. Once the molar volume was determined, the pressure was estimated using Soave's EOS at 293K. Two bubbles in the centre of sample Awere investigated using this single-bubble procedure. All results are reported in Table 4 . The atomic volumes, equivalent to the molar volume, were also calculated, expressed as a number of Schottky defect volumes per gas atoms in the bubble.

\subsubsection{High burn-up fuel - Sample B}

This technique was then tested on a high burn-up fuel. As seen from the SEM images (Fig. 4), bubbles are much smaller and more densely distributed in this sample than in sample A. Because of that, it was not possible to apply directly the previous procedure. 


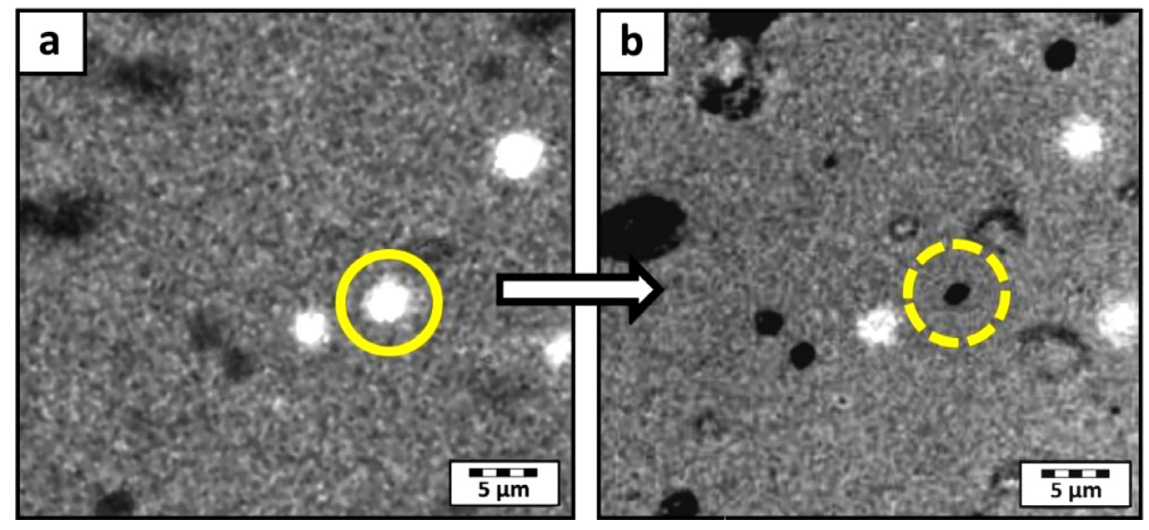

Fig. 8. Sample A - Xenon EPMA maps (a) before, (b) after the SIMS measurement.
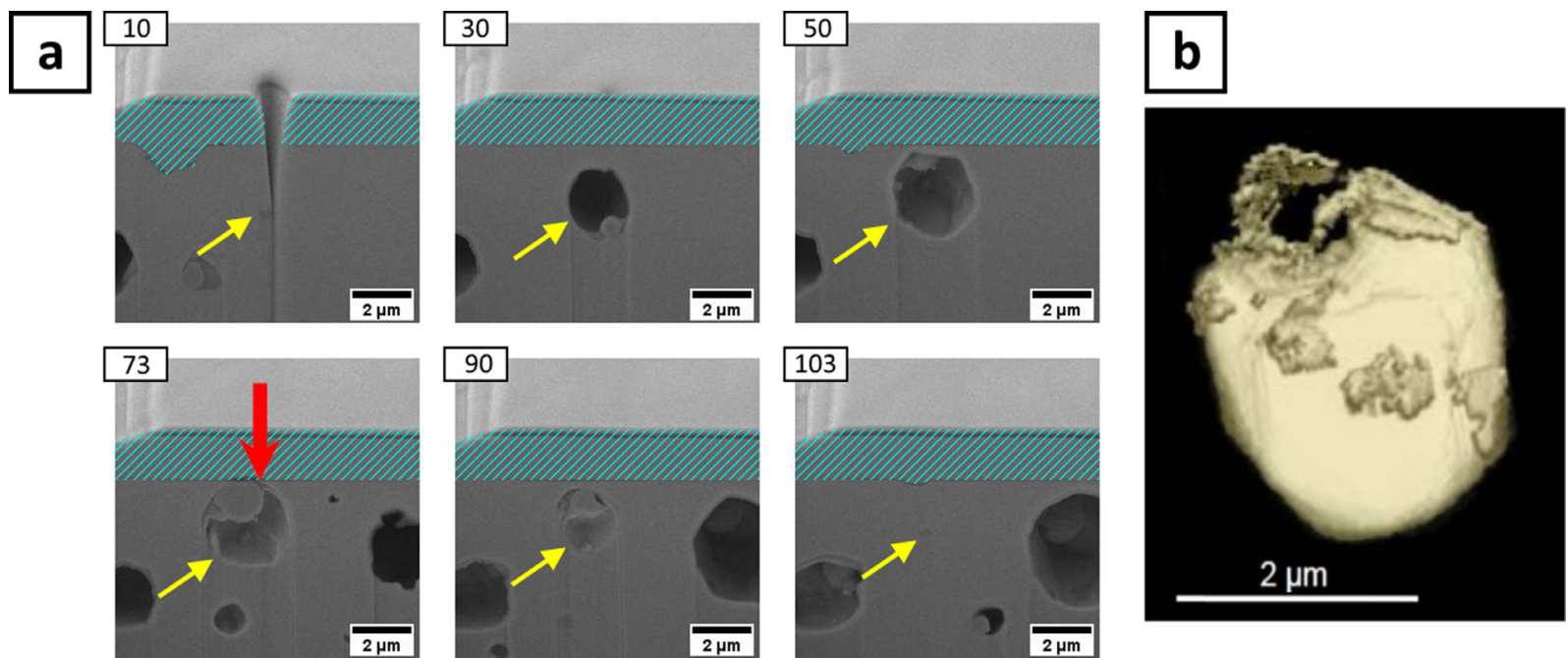

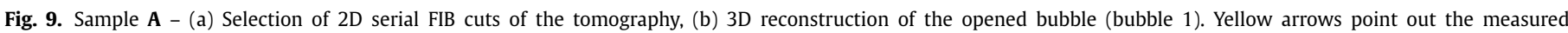
bubble, red arrow points out the bubble opening towards sample surface. Blue hatching covers the platinum layer deposited after the SIMS measurement.

Table 4

Sample A - Results obtained using the single-bubble process.

\begin{tabular}{lll}
\hline & Bubble 1 & Bubble 2 \\
\hline Gas quantity $\mathrm{Xe}+\mathrm{Kr}(\mathrm{mol})$ & $1.03 \times 10^{-13}$ & $1.62 \times 10^{-13}$ \\
Bubble volume $\left(\mu \mathrm{m}^{3}\right)$ & 5.6 & 14.1 \\
Equivalent spheric diameter $(\mu \mathrm{m})$ & 2.2 & 3.0 \\
Molar volume $\left(\mathrm{m}^{3} \cdot \mathrm{mol}^{-1}\right)$ & $5.5 \times 10^{-5}$ & $8.7 \times 10^{-5}$ \\
Atomic volume of fission gases (Schottky defect volume/atom) & $2.2 \Omega$ & $3.5 \Omega$ \\
Pressure at $293 \mathrm{~K}-$ Soave $(\mathrm{MPa})$ & 41.2 & 9.4 \\
\hline
\end{tabular}

As demonstrated in $[23,27]$, the problematic step is the gas quantification $\mathrm{d}$ : it was not possible to restrict the SIMS measurement to one single bubble. Improvements were therefore added in the process to take into account these additional constraints.

To overcome this difficulty, a new step was added, between the selection of the bubble and the problematic measurement with SIMS: in the FIB-SEM, a platinum layer was deposited around the bubble location, thanks to the ion beam of the FIB. The objective was the protection of the surface surrounding the selected bubble, to prevent the SIMS sputtering around it, and the opening of unwanted other bubbles. The platinum acted as a mask for the SIMS beam, limiting the sputtering area to the central hole, where the bubble was located (Fig. 10). This mask has a thickness of $600 \mathrm{~nm}$.

This modified process was applied to sample $\mathbf{B}$, in the centre and on the rim. In total, four bubbles were characterized: two in the central area, one at $0 \mathrm{R}$ and the other at $0.3 \mathrm{R}$, and two in the rim area, at $1 \mathrm{R}$.

\section{Bubble selection}

Steps $\mathrm{a}$ and $\mathrm{b}$, for bubble selections were the same as previously. Then, the platinum masks were deposited using the FIB equipment of the SEM (Fig. 10). The SIMS sputtering area was set at a diameter of about $50 \mu \mathrm{m}$ for a $60 \mathrm{nA}$ primary beam current, therefore the outer diameter of the mask was set to $60 \mu \mathrm{m}$. The inner hole allowing the SIMS beam to sputter the sample, open the bubble and measure its content, had a diameter of $5 \mu \mathrm{m}$.

\section{Gas quantification}

After the SIMS calibration (step c, Fig. 2b), the bubble locations, protected by the platinum mask, were sputtered by SIMS. Only the sputtering time was different, since it was stopped as soon as the opening of the bubble was detected (step d). For each SIMS profile, a unique peak was clearly visible (Fig. 11). The SEM observation of the masks confirmed their integrity: the platinum layer was only superficially sputtered. This validated the platinum deposit 


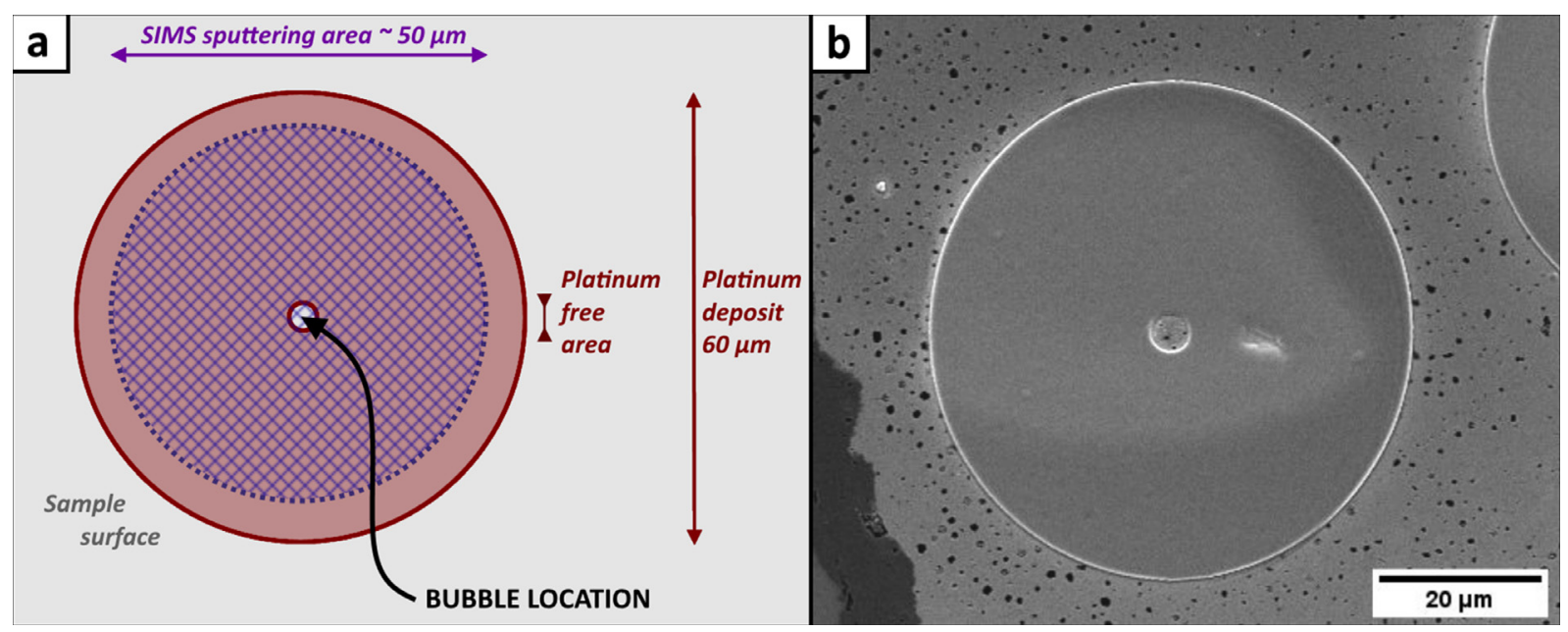

Fig. 10. Sample B - Preparatory steps (a) platinum layer deposit as a mask preventing SIMS sputtering, (b) SEM image of such a platinum deposit on the rim.
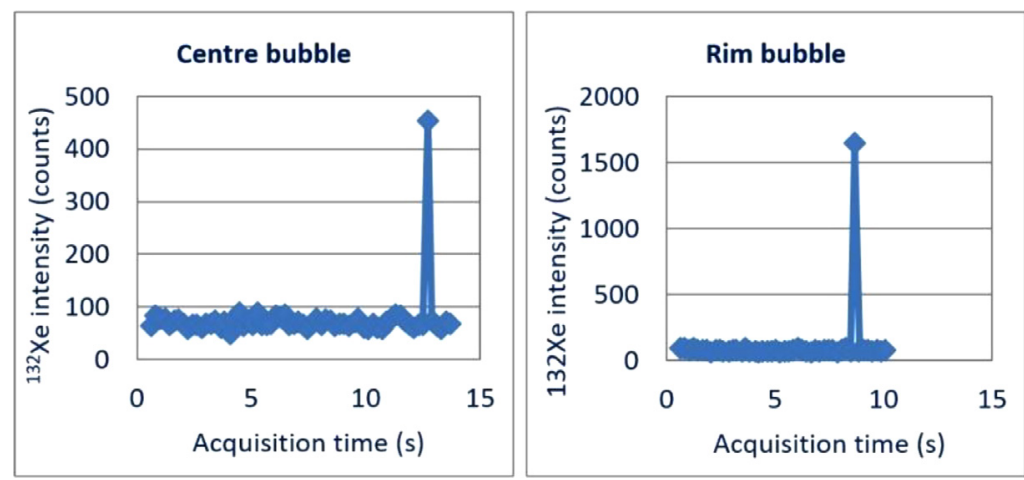

Fig. 11. Sample B - SIMS measurements for a bubble of the centre (OR) and for a bubble of the rim (1R).

Table 5

Sample B - Results of density measurements by single-bubble process.

\begin{tabular}{lllll}
\hline Bubble & 1 & 2 & 3 & 4 \\
\hline Area & $0 \mathrm{R}$ & $0.30 \mathrm{R}$ & $1 \mathrm{R}$ & $1 \mathrm{R}$ \\
Gas quantity $\left(\times 10^{-15} \mathrm{~mol}\right)$ & 3.38 & 3.03 & 13.81 & 14.69 \\
Volume $\left(\mu \mathrm{m}^{3}\right)$ & 0.306 & 0.215 & 0.845 & 1.183 \\
Equivalent spherical diameter ESD $(\mu \mathrm{m})$ & 0.84 & 0.74 & 1.17 & 1.31 \\
Molar volume $\left(\mathrm{m}^{3} \mathrm{~mol}^{-1}\right)$ & $9.04 \times 10^{-5}$ & $7.08 \times 10^{-5}$ & $6.12 \times 10^{-5}$ & $8.05 \times 10^{-5}$ \\
Atomic volume of fission gases $($ Schottky defect volume/atom) & 3.7 & 2.9 & 2.5 & 3.4 \\
Pressure at $293 \mathrm{~K}-$ Soave $(\mathrm{MPa})$ & 8.8 & 14.7 & 25.1 & 9.9 \\
\hline
\end{tabular}

technique. The content of fission gas measured for the two bubbles of the centre and the two bubbles of the rim are reported in Table 5.

\section{Bubble volume}

As in the case of sample A, 3D tomographies by FIB-SEM were used to measure the precise volume of each opened bubble (step f). This was particularly necessary because bubbles in the centre in the high burn-up fuels had complex shapes [7]. Therefore, only a 3D volume measurement was relevant.

As previously, a serial cuts of FIB in the materials, a series of 2D images were acquired on the bubble locations. These series of images, after alignment, formed 3D images of the fuel. Each voxel was a cube of $15 \mathrm{~nm}$ side. A secondary electron detector is used to acquire the images of each cut, with a beam acceleration voltage of $2 \mathrm{kV}$. A selection of these 2D images of cuts are presented in Fig. 12a for the bubble of the centre (OR). On each image, the thin platinum layer deposited as mask is visible (double-hatched in green), as well as a second, thicker, platinum layer, deposited after the SIMS measurement and necessary in the SEM tomogra- phy process (hatched in blue). Furthermore, in Fig. 12a, a yellow arrow points out the measured bubble on each image. The bubble appears for the first time in slice 220 and ends in slice 332 . As expected, the bubble was just below the surface and had a very small opening towards the surface (red vertical arrow on slice 264). 3D reconstruction gave the volume of the bubble (Fig. 12b), completing step e. The bubble selected in the centre was quite flat, far from a spherical shape. For indication, its sphericity was 0.11 , and its geodesic diameter and diameter of the biggest inscribed sphere were respectively $1.91 \mu \mathrm{m}$ and $0.36 \mu \mathrm{m}$. Its volume was $0.31 \mu \mathrm{m}^{3}$, corresponding to an equivalent spherical diameter (ESD) of $0.84 \mu \mathrm{m}$.

The same process was applied for the bubble on the rim. Fig. 13 shows the $3 \mathrm{D}$ reconstruction of the bubble volume. It was closer to a spherical-shape, but the surface was influenced by surrounding small grains. This surrounding resulted in a low sphericity value of 0.25 , but its compact shape was evidenced by the bubble geodesic diameter of $1.64 \mu \mathrm{m}$ and the values of the biggest inscribed sphere of $0.93 \mu \mathrm{m}$, two values close to the ESD $1.17 \mu \mathrm{m}$. 

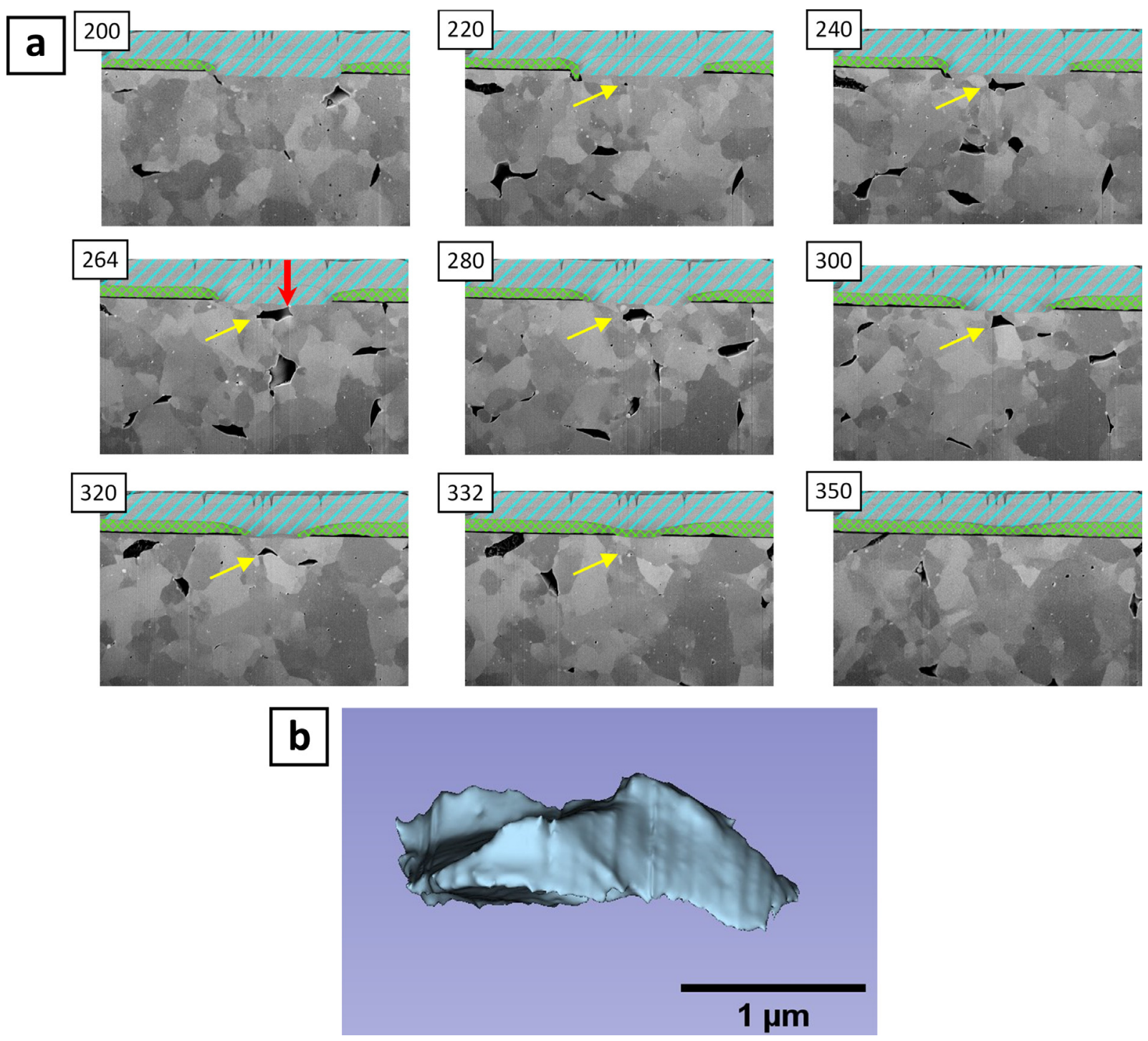

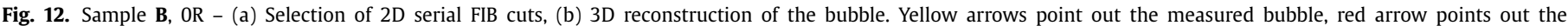

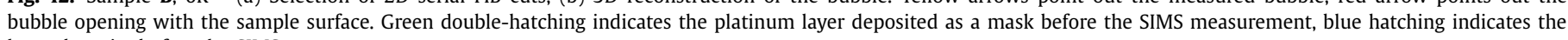
layer deposited after the SIMS measurement.

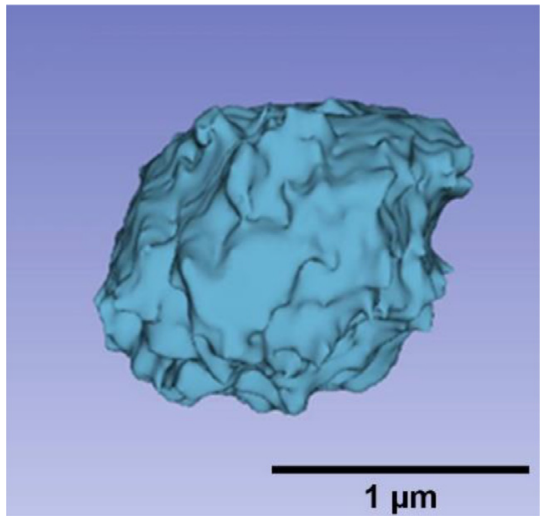

Fig. 13. Sample B - 3D reconstruction of the bubble on the rim.

Results. The same method as in 0 was used to calculate the molar volume and the pressure of the fission gases in the four investigated bubbles. The results for the four bubbles at different radial positions are summarized in Table 5.

\section{Discussion}

This work has shown the possibility of implementing a "singlebubble" process, even in the case of high burn-up fuels presenting a high density of small bubbles. In addition to the gas molar volume in selected bubbles, it also gives the volume, size and shape of these bubbles. Also, it allows to focus on bubbles really full of gas. It is therefore a way to have access to parameters possibly linked with the pressure, such as the bubble volume, even with complex shapes. The results obtained by using this method are more precise than the mean pressure evaluations, and complementary to it. The main disadvantage of this single-bubble methodology is that it is a long and difficult process, limiting the number of measurements.

In the case of sample $\mathbf{A}$, the three measurements (mean value and values for the two single bubbles) were consistent, with the same order of magnitude. The mean pressure estimated to 20.5 MPa lied between the two single-bubble pressures, 41.2 and 9.4 MPa respectively. Regarding the single-bubbles themselves, the most pressurized bubble had the smallest size, as expected. However, the evolution of the pressures of the two bubbles did not fol- 


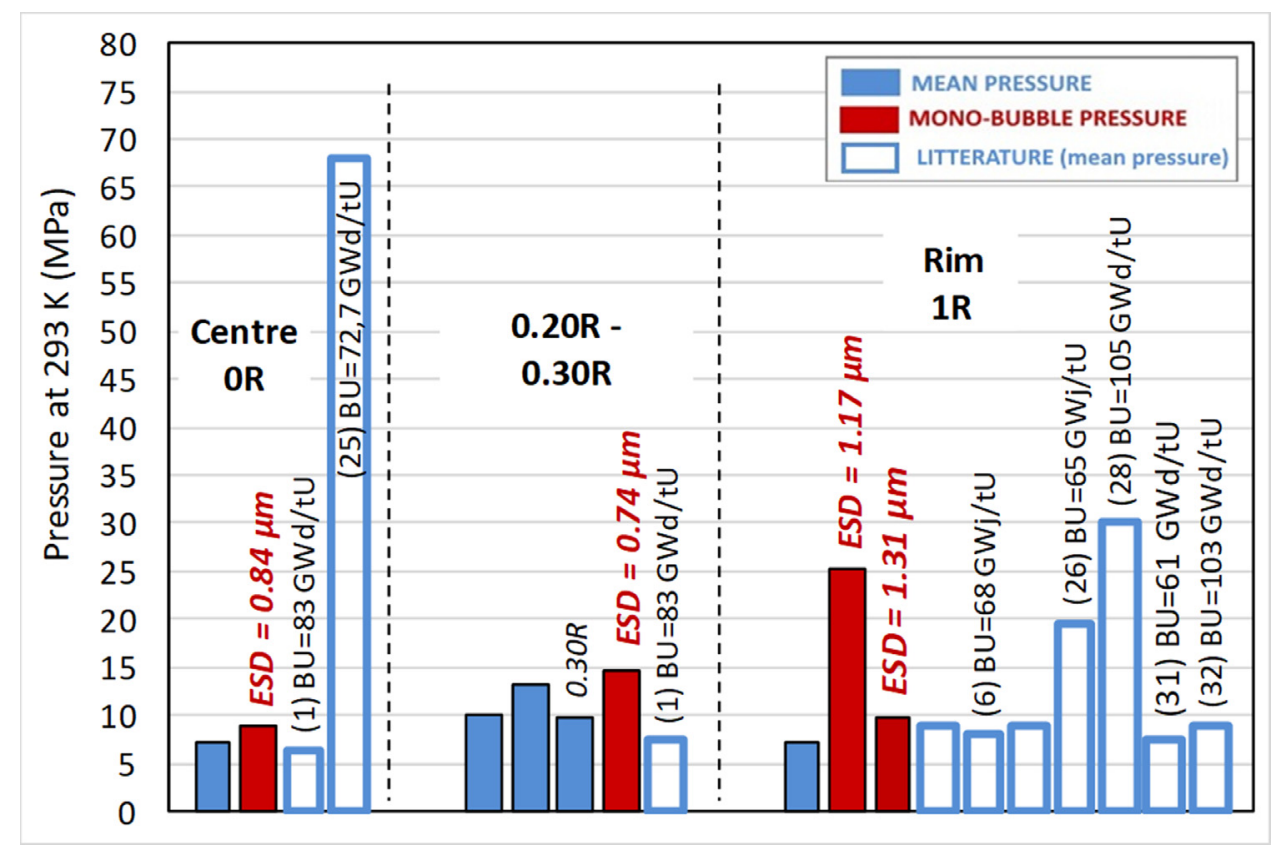

Fig. 14. Comparison of the mean pressures and single-bubble results for high burn-up fuels.
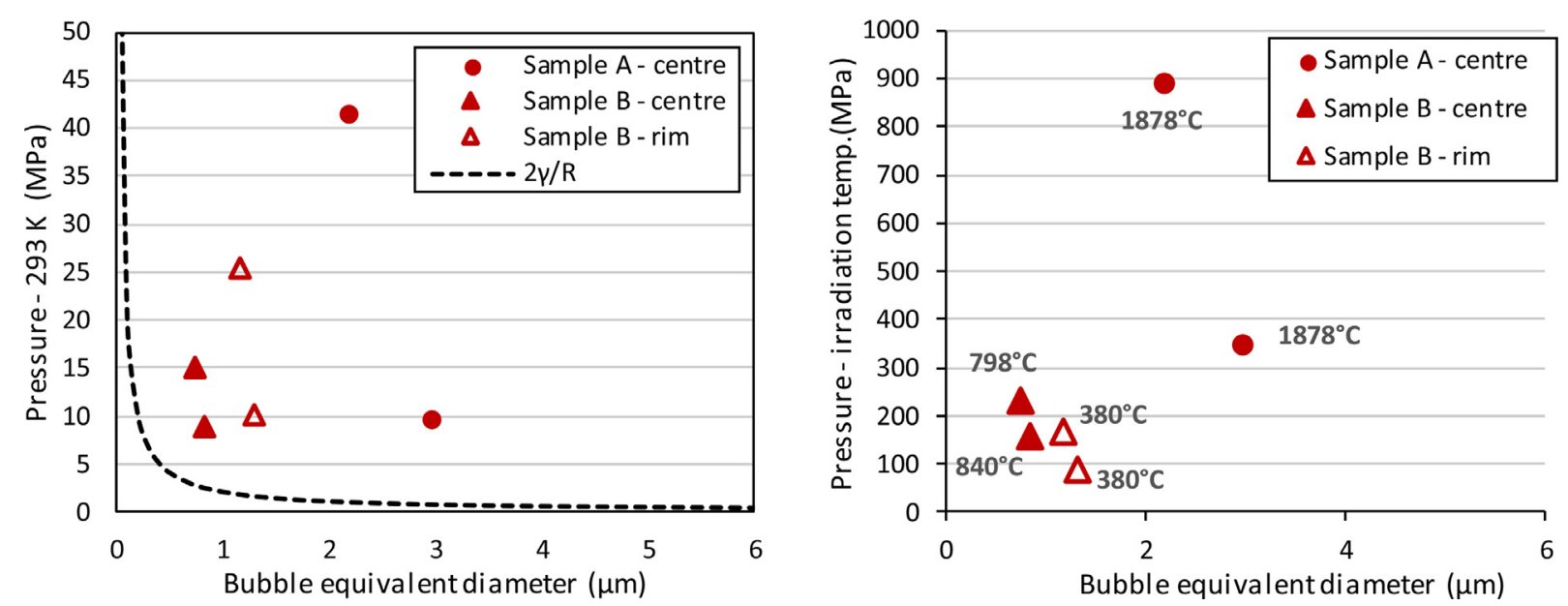

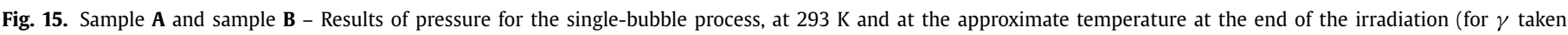
as $1 \mathrm{~N} / \mathrm{m}$ ).

low the trend of $2 \gamma / \mathrm{R}$, since they exhibited a 4.4 pressure ratio for a radius ratio lower than 1.4 .

Concerning the size of the bubbles, it can be compared to the size distribution obtained by 2D SEM images of the sample A surface. At $\mathrm{OR}$, the most represented class (in terms of percent surface area) was that of the bubbles with an equivalent circular diameter of 2.0-2.2 $\mu \mathrm{m}$. Note that only the bubble cross-section with the surface was considered, so the actual representative diameter was probably slightly larger. The two single-bubbles were therefore on either side of this majority size class. Consequently, it was expected that the pressure results would reproduce this order, with the mean pressure between the two single-bubble pressures.

Fig. 14 provides a comparison between the mean pressure and the single-bubble pressure results for high burn-up fuels, i.e. sample B, as compared to some data from the literature. Again, for this sample, for the two single-bubbles of the centre (OR and 0.30R), and for the two single-bubbles of the rim (1R), the smallest bubble had a higher pressure than the biggest one. Likewise, for each radial position, the values obtained by the two methods (mean and single-bubble) were similar. The pressure values coming from the literature were also in the same order of magnitude (except for one higher value in the centre for a sample at $72.7 \mathrm{GWd} / \mathrm{t}_{U}$ ), although showing some dispersion.

However, it must be noticed that in these cases, the singlebubble pressures were systematically higher than the corresponding mean pressure, whereas the bubbles characterized were among the large bubbles in the local size distributions. Indeed, 2D analyses of the SEM images for sample $\mathbf{B}$, at $0 \mathrm{R}, 0.30 \mathrm{R}$ and $1 \mathrm{R}$, showed that the most represented equivalent circular diameter class, in terms of percent surface, were respectively $0.5-0.6 \mu \mathrm{m}, 0.2-0.3 \mu \mathrm{m}$, and $0.8-0.9 \mu \mathrm{m}$. Considering this, we would expect that the gas pressures in the measured single-bubbles, with higher diameters, were lower or equal, and not systematically higher, than the mean pressure. This could indicate an overestimation of single-bubble pressure, or, more likely, an underestimation of the mean pressure for high burn-up fuels. This underestimation could be due to the existence of fabrication pores smaller than $3 \mu \mathrm{m}$ which would bias the resulting pressure, or to an overestimation of to- 
tal bubble porosity due to polishing effects or to image analysis bias.

The pressure results obtained by the single-bubble methodology for the two samples are reported in Fig. 15, as a function of the bubble equivalent diameter. For each bubble the pressure was calculated at ambient temperature, but also at the local temperature at the end of the irradiation. Consistently with previous mean results, all these pressures are higher than $2 \gamma / \mathrm{R}$, therefore bubbles are over-pressurized, even at room temperature. In addition, the bubbles from sample A, $\left(12 \mathrm{~h}\right.$ plateau at $\left.470 \mathrm{~W} \cdot \mathrm{cm}^{-1}\right)$ showed the highest pressures when calculated for the central temperature at the end of the power ramp plateau. The gases in the bubbles were therefore still over-pressurised at the end of the ramp. For sample B, although HBS bubbles were larger than the bubbles in the centre, at $293 \mathrm{~K}$, their pressure can be higher. However, when taking into account the local temperature at the end of the irradiation, the trend is reverse. Even taking into account the local temperatures at the end of the irradiation and considering the case of sample B bubbles only, this limited set of "single-bubble" measurements tends to show that there is no direct link between bubble size and bubble content for all radial positions. This is not necessarily surprising, as the mechanisms inducing the formation of these bubbles are different.

\section{Conclusion}

Two methodologies were used to measure fission gas densities in micrometric bubbles in irradiated nuclear fuel samples. These two methods combine three devices in a high activity laboratory: FIB-SEM, EPMA and SIMS.

The first method was used to measure the mean gas density in bubbles as a function of the local radial position in two samples. The results were compared to data from the literature.

The second method, called here the "single-bubble" process was developed in this work. It can be applied to any irradiated nuclear fuel. In this work, it was applied to a PWR $\mathrm{UO}_{2}$ fuel after a power ramp and a $\mathrm{PWR} \mathrm{UO}_{2}$ high burn-up fuel. It provides values for the fission gas densities inside selected micrometric bubbles. From these gas densities, gas pressures can be obtained using the relevant equation of state. The feasibility of the process on single bubbles was demonstrated, and the pressure was measured for six bubbles distributed in two samples. The results obtained for these two fuels were similar for the two methods, but question a possible underestimation of pressure for the mean gas density method, more likely than an overestimation for the "single-bubble" method. New bubbles in other irradiated samples, exhibiting various bubble concentrations and bubble size and shapes must now be investigated to enrich this, still limited, set of data.

\section{Declaration of Competing Interest}

The authors declare that they have no known competing financial interests or personal relationships that could have appeared to influence the work reported in this paper.

\section{Acknowledgments}

The authors are grateful to EDF and Framatome for their support in the studies by providing studied irradiated fuels that they made and used in nuclear power plants.

FIJI [33,34], ilastik [35] and 3Dslicer [36] (http://www.slicer.org) have been used in the image processing.

\section{References}

[1] J. Noirot, et al., High burn-up change in UO2 fuels irradiated up to 83 GWd/tUin M5 claddings, Nuclear Engineering and Technology 41 (2) (2009) 155-162, doi:10.5516/NET.2009.41.2.155.
[2] J. Rest, M.W.D. Cooper, J. Spino, J.A. Turnbull, P. Van Uffelen, C.T. Walker, Fission gas release from $\mathrm{UO}_{2}$ nuclear fuel: A review, Journal of Nuclear Materials (Aug. 2018), doi:10.1016/j.jnucmat.2018.08.019.

[3] F. Cappia, et al., Critical assessment of the pore size distribution in the rim region of high burnup $\mathrm{UO}_{2}$ fuels, Journal of Nuclear Materials 480 (Nov. 2016) 138-149, doi:10.1016/j.jnucmat.2016.08.010.

[4] J. Noirot, L. Desgranges, J. Lamontagne, Detailed characterisations of high burnup structures in oxide fuels, Journal of Nuclear Materials 372 (2) (Jan. 2008) 318-339, doi:10.1016/j.jnucmat.2007.04.037.

[5] R.M. Cornell, An electron microscope examination of matrix fission-gas bubbles in irradiated uranium dioxide, Journal of Nuclear Materials 38 (3) (Mar. 1971) 319-328, doi:10.1016/0022-3115(71)90061-4.

[6] H. Stehle, Performance of oxide nuclear fuel in water-cooled power reactors, Journal of Nuclear Materials 153 (Apr. 1988) 3-15, doi:10.1016/0022-3115(88) 90187-0.

[7] J. Noirot, I. Zacharie-Aubrun, T. Blay, Focused ion beam-scanning electron microscope examination of high burn-up $\mathrm{UO}_{2}$ in the center of a pellet, Nuclear Engineering and Technology 50 (2) (Mar. 2018) 259-267, doi:10.1016/j.net.2017. 12.002.

[8] N. Lozano, L. Desgranges, D. Aymes, J.C. Niepce, High magnification SEM observations for two types of granularity in a high burnup PWR fuel rim, Journal of Nuclear Materials 257 (1) (Sep. 1998) 78-87, doi:10.1016/S0022-3115(98) 00056-7.

[9] Hj. Matzke, On the rim effect in high burnup $\mathrm{UO}_{2}$ LWR fuels, Journal of Nuclear Materials 189 (1) (Jul. 1992) 141-148, doi:10.1016/0022-3115(92)90428-N.

[10] R.J. White, The development of grain-face porosity in irradiated oxide fuel, Journal of Nuclear Materials 325 (1) (Feb. 2004) 61-77, doi:10.1016/j.jnucmat. 2003.10.008.

[11] J. Papin, et al., Summary and Interpretation of the CABRI REP-Na Program, Nuclear Technology 157 (3) (Mar. 2007) 230-250, doi:10.13182/NT07-A3815.

[12] J. Noirot, T. Blay, J. Lamontagne, L. Fayette, Y. Pontillon, and X. Pujol, 'Size and radial origin of fragments formed while heating a $83 \mathrm{GWd} / \mathrm{tU}$ PWR fuel up to $1200^{\circ} \mathrm{C}^{\prime}, 2015$.

[13] I. Guénot-Delahaie, et al., Simulation of reactivity-initiated accident transients on $\mathrm{UO}_{2}-\mathrm{M} 5{ }^{\circledR}$ fuel rods with ALCYONE V1.4 fuel performance code, Nuclear Engineering and Technology 50 (2) (Mar. 2018) 268-279, doi:10.1016/j.net.2017. 12.006.

[14] P. Lösönen, On the behaviour of intragranular fission gas in $\mathrm{UO}_{2}$ fuel, Journal of Nuclear Materials 280 (1) (Jun. 2000) 56-72, doi:10.1016/S0022-3115(00) 00028-3.

[15] L. Noirot, MARGARET: A comprehensive code for the description of fission gas behavior, Nuclear Engineering and Design 241 (6) (Jun. 2011) 2099-2118, doi:10.1016/j.nucengdes.2011.03.044.

[16] L. Noirot, MARGARET: An Advanced Mechanistic Model of Fission Gas Behavior in Nuclear Fuel, Journal of Nuclear Science and Technology 43 (9) (Mar. 2006) $1149-1160$.

[17] D.R. Olander, D. Wongsawaeng, Re-solution of fission gas - A review: Part I. Intragranular bubbles, Journal of Nuclear Materials 354 (1) (Aug. 2006) 94109, doi:10.1016/j.jnucmat.2006.03.010.

[18] C. Ronchi, C.T. Walker, Determination of xenon concentrations in nuclear fuels by electron microprobe analysis, J. Phys. D: Appl. Phys. 13 (12) (Dec. 1980) 2175-2184, doi:10.1088/0022-3727/13/12/004.

[19] C.T. Walker, S. Bremier, S. Portier, R. Hasnaoui, W. Goll, SIMS analysis of an $\mathrm{UO}_{2}$ fuel irradiated at low temperature to $65 \mathrm{MWd} / \mathrm{kgHM}$, Journal of Nuclear Materials 393 (2) (Sep. 2009) 212-223, doi:10.1016/j.jnucmat.2009.06.017.

[20] M. Horvath, et al., Analysis of xenon gas inclusions in nuclear fuel using laser ablation ICP-MS, J. Anal. At. Spectrom. 22 (10) (Sep. 2007) 1266-1274, doi:10. 1039/B705533A.

[21] J. Noirot, et al., Fission gas inventory in PWR high burnup fuel : Experimental characterization and modeling, presented at the International Meeting on LWR Fuel Performance, Sep. 2004.

[22] J. Noirot, Y. Pontillon, S. Yagnik, J.A. Turnbull, T. Tverberg, Fission gas release behaviour of a $103 \mathrm{GWd} / \mathrm{tHM}$ fuel disc during a $1200^{\circ} \mathrm{C}$ annealing test, Journal of Nuclear Materials 446 (1) (Mar. 2014) 163-171, doi:10.1016/j.jnucmat.2013. 12.002.

[23] C. Cagna, 'Influence des gaz de fission sur l'état mécanique des combustibles oxydes irradiés', Ph.D. thesis, Ecole nationale supérieure d'arts et métiers - ENSAM, 2016

[24] M. Horvath, 'Development of a method for xenon determination in the microstructure of high burn-up nuclear fuel', Ph.D. thesis, Swiss Federal Institute of Technology, 2007.

[25] M. Boidron, M. Tourasse, F. Boussard, J.P. Piron, B. Pasquet, Microprobe measurement calibration of absorbed xenon in a PWR fuel, in: Proceedings of the International Topical Meeting on LWR Fuel Performance, 1991, pp. 21-24.

[26] L. Desgranges, B. Pasquet, Measurement of xenon in uranium dioxide $\left(\mathrm{UO}_{2}\right)$ with SIMS, Nuclear Instruments and Methods in Physics Research Section B: Beam Interactions with Materials and Atoms 215 (3) (Feb. 2004) 545-551, doi:10.1016/j.nimb.2003.08.033.

[27] J. Lamontagne, J. Noirot, L. Desgranges, T. Blay, B. Pasquet, I. Roure, Detection of gas bubble by SIMS in irradiated nuclear fuel, Microchim. Acta 145 (1) (Apr. 2004) 91-94, doi:10.1007/s00604-003-0135-9.

[28] L. Desgranges, C. Valot, B. Pasquet, J. Lamontagne, T. Blay, I. Roure, A method for the quantification of total xenon concentration in irradiated nuclear fuel with SIMS and EPMA, Nuclear Instruments and Methods in Physics Research Section B: Beam Interactions with Materials and Atoms 266 (1) (Jan. 2008) 147-154, doi:10.1016/j.nimb.2007.10.035. 
[29] J. Vidal, J.-P. Grouiller, A. Launay, Y. Berthion, A. Marc, H. Toubon, CESAR: A Code for Nuclear Fuel and Waste Characterisation, presented at the WM'06 Conference, Feb. 2006.

[30] N. Otsu, A threshold selection method from gray-level histograms, IEEE Transactions on Systems, Man, and Cybernetics 9 (1) (Jan. 1979) 62-66, doi:10.1109/ TSMC.1979.4310076.

[31] M.D. Freshley, D.W. Brite, J.L. Daniel, P.E. Hart, Irradiation-induced densification of $\mathrm{UO}_{2}$ pellet fuel, Journal of Nuclear Materials 62 (2) (Nov. 1976) 138-166, doi:10.1016/0022-3115(76)90013-1.

[32] C. Cagna, I. Zacharie-Aubrun, P. Bienvenu, L. Barrallier, B. Michel, J. Noirot, A complementary approach to estimate the internal pressure of fission gas bubbles by SEM-SIMS-EPMA in irradiated nuclear fuels, IOP Conf. Ser.: Mater. Sci. Eng. 109 (Feb. 2016) 012002, doi:10.1088/1757-899X/109/1/012002.
[33] J. Schindelin, et al., Fiji: an open-source platform for biological-image analysis, Nature Methods 9 (7) (Jul. 2012) 676-682, doi:10.1038/nmeth.2019.

[34] C.T. Rueden, et al., ImageJ2: Image for the next generation of scientific image data, BMC Bioinformatics 18 (1) (Nov. 2017) 529, doi:10.1186/ s12859-017-1934-z.

[35] S. Berg, et al., ilastik: interactive machine learning for (bio)image analysis, Nature Methods 16 (12) (Dec. 2019) 1226-1232, doi:10.1038/s41592-019-0582-9.

[36] A. Fedorov, et al., 3D Slicer as an Image Computing Platform for the Quantitative Imaging Network, Magn Reson Imaging 30 (9) (Nov. 2012) 1323-1341, doi:10.1016/j.mri.2012.05.001. 